\title{
The synergy between TB and HIV co-infection on perceived stigma in Ethiopia
}

Amare Deribew $^{1 *}$, Yohannes HaileMichael ${ }^{2}$, Markos Tesfaye ${ }^{3}$, Dejene Desalegn ${ }^{4}$, Ajeme Wogi $^{5}$, Shallo Daba ${ }^{5}$

\begin{abstract}
Background: The synergy between tuberculosis (TB) and human immunodeficiency virus (HIV) co-infection on perceived stigma is not well studied. The objective of this study was to assess the effect of TB/HIV co-infection on perceived stigma in selected hospitals of Oromiya region, Ethiopia. A cross sectional study was conducted from February to April, 2009 in Adama, Nekemet and Jimma Specialized hospitals. Data were collected by trained HIV counselors. A structured questionnaire which consisted of socio-demographic variables, clinical information, perceived stigma, and depression was used to collect the data

Findings: A total of 591 participants were included in the study of whom 124 (20.9\%) were co-infected with TB/ HIV. The stigma items were highly reliable (Cronbach's alpha $=0.93$ ) and had strong inter dimension correlation. Respondents who were co-infected with TB and HIV were more likely to have perceived stigma compared to nonco-infected HIV patients, $[\mathrm{OR}=1.4,(95 \% \mathrm{Cl}: 1.2,2.0)]$. Non-literate individuals $[\mathrm{OR}=1.9,(95 \% \mathrm{Cl}: 1.2,3.0)]$ and females $[\mathrm{OR}=1.6,(95 \% \mathrm{Cl}: 1.2,2.3)]$ had also more perceived stigma.

Conclusions: TB/HIV co-infected patients, non-literate individuals and females were more likely to have high perceived stigma. Behavioral Change Communication should focus on these segments of the population to rectify the high perceived stigma.
\end{abstract}

\section{Background}

The extensive nature of stigma against people with AIDS is well established [1,2]. People living with HIV/ AIDS (PLHA) have been stigmatized worldwide since the beginning of the epidemic; leading to severe social consequences related to their rights, health care services, freedom, self identity and social interactions [1]. Stigma and discrimination related to HIV/AIDS would undermine public health efforts to combat the epidemic. The UN stated that stigma against PLHA still hamper prevention, care and treatment efforts everywhere [2].

The literature showed that perceived HIV stigma has a negative and constant impact on life satisfaction [3] and quality of life [4,5]. HIV related stigma has been correlated with poorer mental health outcomes, lowered selfesteem, lowered self-efficacy, and decreased adherence to antiretroviral treatments [6].

Several studies have been conducted on the consequences of stigma [7] and its effect on receiving HIV/

\footnotetext{
* Correspondence: amare_deribew@yahoo.com

'Department of Epidemiology, Jimma University, Jimma, Ethiopia

Full list of author information is available at the end of the article
}

AIDS related services [8,9]. However, little is known about the synergy between TB and HIV co-infection on perceived stigma. The present study assessed effect of TB/HIV co-infection on perceived stigma towards TB/ HIV co-infection.

\section{Methods}

From February to April, 2009, we conducted a cross sectional study in three hospitals in Ethiopia. A detail method of the study is published elsewhere [10]. In brief, the study was conducted in Adama, Nekemet and Jimma specialized hospitals located at the east, west and southwest part of Ethiopia. The study population consisted of $155 \mathrm{~TB} / \mathrm{HIV}$ co infected and 465 HIV patients. During the study period, new TB patients $(\mathrm{n}=124)$ in each TB/HIV clinic of the hospitals were included. For each TB/HIV co-infected patient, 3 HIV patients with no TB were included. The non-co-infected HIV patients were selected using a simple random sampling technique using the patients' unique identification number in the HIV clinics. The exclusion criteria for both groups 
included age less than 15 years and presence of known chronic illnesses like diabetes mellitus and hypertension.

A structured questionnaire was used to collect information from the respondents. The content of the questionnaire included socio-demographic variables, clinical information, social support, perceived stigma and depression. Perceived stigma was measured by 23 Likert scale items adopted from Berger et al [11].

Data were entered into computer and analyzed using SPSS version 15.0 software. The stigma questions were scaled in positive direction where higher score denotes high perceived stigma. A total stigma score was created by summing all the scores of the stigma questions. The mean was calculated from the total stigma score and individuals who scored below the mean were categorized as having 'low' perceived stigma. Those who scored above the mean were categorized as having 'high' perceived stigma. Bivariate analysis was computed to identify factors associated with perceived stigma. To control the effect of confounding variables, stepwise logistic regression model was done to identify predictors of perceived stigma. Variables which had statistically significant association in the bivariate analysis were candidates for the multivariate logistic regression model. Interaction between variables were tested but are not reported as none were significant.

Ethical clearance was obtained from Jimma University ethical review board. The purpose of the study was explained to the respondents. Written consent was obtained from the study participants. To ensure confidentiality, codes were anonymous.

\section{Results}

Of the 620 eligible respondents, complete data were obtained from 591 (95\%) of them. One hundred twenty four $(20.9 \%)$ of the study participants were co-infected with TB and HIV. From the planned 155 TB/HIV coinfected patients, only 124 of them were interviewed and the rest 31 patients lost to follow up. Of the coinfected patients, $61(49.2 \%)$ and $42(33.8 \%)$ had smear negative and positive TB respectively. About two third (67.2\%) of the patients had CD4 lymphocyte count of less than $200 / \mu \mathrm{L}$. Of the total participants, $107(18 \%)$ and $355(60 \%)$ were in the $2^{\text {nd }}$ and $3^{\text {rd }}$ stage of the WHO clinical stage classification respectively.

The Majority, 344 (58.2\%) of the study participants were females. The mean age of the respondents was 33.4 years (SD \pm 8.1$)$. Nearly half $276(46.7 \%)$ of the respondents were in the age group of 25-34 years (Table-1).

More than half of the respondents (56\%) had high perceived stigma. The Multivariate analysis predicted that there was a significant relationship between perceived stigma and TB/HIV co-infection, depression, level of education and gender. Respondents who were
Table 1 Socio-demographic characteristics of the study population in three hospitals of Oromia, March, 2009, ( $N=591)$

\begin{tabular}{ll}
\hline Variables & Number (\%) \\
\hline Age in Years & $54(9.1)$ \\
$15-24$ & $276(46.7)$ \\
$25-34$ & $261(44.2)$ \\
$>=35$ & \\
Sex & $247(41.8)$ \\
$\quad$ Male & $344(58.2)$ \\
Female & \\
Educational status & $104(17.6)$ \\
Illiterate & $487(82.4)$ \\
literate & \\
Occupation & $68(11.4)$ \\
Government employee & $99(16.8)$ \\
Private employee & $79(13.4)$ \\
Merchant & $45(7.6)$ \\
Farmer & $94(15.9)$ \\
Housewives & $115(19.5)$ \\
Daily laborer & $91(15.4)$ \\
No Job &
\end{tabular}

co-infected with TB and HIV were 1.4 times more likely to have high perceived stigma as compared to non-coinfected HIV patients, [OR $=1.4,(95 \% \mathrm{CI}: 1.2,2.0)]$. Non-literate individuals were 2 times more likely to experience high perceived stigma than literates, $[\mathrm{OR}=$ 1.9, (95\% CI: 1.2, 3.0)]. Individuals who had depression were 2.3 times more likely to have high perceived stigma than non-depressed individuals [OR $=2.3 ;(95 \% \mathrm{CI}: 1.5$, 3.2)]. Women had higher perceived stigma than men [OR = 1.6, (95\% CI: 1.2, 2.3)] (Table-2).

Age, Social support, income, CD4 lymphocyte count, and WHO staging didn't have statistically significant association with perceived stigma.

Table 2 Predictors of perceived stigma among HIV patients in three hospitals of Oromia, March, 2009

\begin{tabular}{|c|c|c|c|}
\hline \multirow[t]{2}{*}{ Variable } & \multicolumn{2}{|c|}{ Perceived stigma } & \multirow[b]{2}{*}{ Adjusted OR(95\%Cl) } \\
\hline & High & Low & \\
\hline \multicolumn{4}{|c|}{ TB/HIV co-infection } \\
\hline Yes & 70 & 54 & $1.4(1.1,2.0)$ \\
\hline NO & 202 & 265 & 1 \\
\hline \multicolumn{4}{|l|}{ Depression } \\
\hline Yes & 165 & 132 & $2.3(1.5,3.2)$ \\
\hline No & 107 & 187 & 1 \\
\hline \multicolumn{4}{|l|}{ Education } \\
\hline Illiterate & 62 & 42 & $1.9(1.2,3.0)$ \\
\hline literate & 210 & 277 & \\
\hline \multicolumn{4}{|l|}{ Gender } \\
\hline Female & 176 & 168 & $1.6(1.2,2.3)$ \\
\hline Male & 96 & 151 & 1 \\
\hline
\end{tabular}




\section{Discussion}

This study identified factors associated with perceived stigma in HIV patients. More than half of our study participants had experienced high perceived stigma. This figure is much higher than the finding of Vissel et al (33\%) in South Africa [12]. However, the burden of stigma by other people (negative reaction towards PLHA) might be lower than the perceived stigma in Ethiopia. A study done in India found that actual stigma was much lower than perceived stigma [13]. The high proportion of people with high perceived stigma in our setting could have negative consequences on adherence to antiretroviral therapy and other HIV/AIDS related care $[8,9,13]$ and disclosure of the HIV status of individuals [14]. Self stigmatized people might develop negative attitude towards health professionals and health care and are less likely to disclose their HIV status and could spread the virus to others [14].

A study in South Africa showed that older individuals, males and the less educated ones were more likely to had high perceived stigma [12]. In our study, non-literate individuals and females were more likely to have high perceived stigma. The low social status and economic dependency of women and non-literate individuals in our country could act in synergy with TB/HIV co-infection to increase the perceived stigma among women and nonliterate individuals. Unlike other studies $[14,15]$, we did not show an association between age and income with perceived stigma. The literature showed that social support is a good buffer in reducing perceived stigma [15]. However, our study couldn't prove this hypothesis.

People with mental health problems are at higher risk of experiencing perceived stigma $[15,16]$. However, in our study, stigma could be also the risk factor for depression. Internalized shame and feeling of guilty is one of the predictor of depression or other form of mental distress [16].

TB/HIV co-infected patients were more likely to have perceived stigma. The literature showed that people with TB have been discriminated and isolated from the society for fear of infection [17]. Co-infected patients might perceive that the community would avoid them for fear of infection in our setting. This double burden stigma of TB might aggravate the already existing perceived stigma due to HIV. WHO staging and lower CD4 lymphocyte count didn't show significant association with perceived stigma in our setting. Other literature showed that clinical stage was one of the predictors of perceived stigma [15].

Although we tried to document the effect of TB/HIV co-infection on perceived stigma for the first time, our finding didn't include survey on actual stigma and qualitative study to triangulate the findings.

\section{Conclusions}

More than half of the study participants had high perceived stigma. Non-literate individuals, females and TB/ HIV coinfected patients were more likely to have high perceived stigma. Behavioral Change Communication should focus on these segments of the population to reduce perceived stigma.

\section{Acknowledgements}

The authors acknowledge the HIV Prevention and Control Office of the Oromiya regional Health Bureau of Ethiopia for funding the study. The authors appreciate the study participants for their cooperation in providing the necessary information.

\section{Author details}

${ }^{1}$ Department of Epidemiology, Jimma University, Jimma, Ethiopia.

${ }^{2}$ Department of Health Service management, Jimma University, Jimma, Ethiopia. ${ }^{3}$ Department of psychiatry, Jimma University, Jimma, Ethiopia. ${ }^{4}$ Nekemet Hospital, Nekemet, Ethiopia. ${ }^{5}$ Oromiya Regional Health Bureau, Addis Ababa, Ethiopia.

\section{Authors' contributions}

AD Conceived the study and was involved in the design, analysis and report writing. YH was involved in data analysis and report writing. MT was involved in the design of the study and critically reviewed the article. AW, SD and DD were involved in field activities and reviewed the article. All authors read and approved the manuscript.

\section{Competing interests}

The authors declare that they have no competing interests.

Received: 18 January 2010 Accepted: 4 October 2010

Published: 4 October 2010

\section{References}

1. Mawar N, Sahay S, Pandit A, Mahajan U: The Third phase HIV pandemic: Social consequences of HIV/AIDS stigma \& discrimination \& future needs. Indian J Med Research 2005, 122:471-484.

2. WHO/UNAIDS: Progress on Global Access to HIV Antiretroviral therapy: A report on "3 by 5" and beyond. WHO, Geneva 2006.

3. Greeff $M$, Leana $R$, Wantland D, Makoae L, Chirwa M, Dlamini P, Kohi T, Mullan J: Perceived HIV stigma and life satisfaction among persons living with HIV infection in five African countries: A longitudinal study. Int $J$ Nurs Stud 2009, in press.

4. Buseh AG, Kelber ST, Hewitt JB, Stevens PE, Park CG: Perceived stigma and life satisfaction: Experiences of urban African American men living with HIV/AIDS. International Journal of Men's Health 2006, 5(1):35-51.

5. Perlick DA, Rosenheck RA, Clarkin JF, Sirey JA, Salahi J, Struening EL, Link BG: Stigma as a barrier to recovery: adverse effects of perceived stigma on social adaptation of persons diagnosed with bipolar affective disorder. Psychiatr Serv 2001, 52:1627-1632.

6. Baird ST, Bogart LM, Delahanty DL: Health-related correlates of perceived discrimination in HIV care. AIDS Patient Care and STDs 2004, 18(1):19-26.

7. Chesney MA, Smith AW: Critical delays in HIV testing and care. American Behavioral Scientist 1999, 42:1158-1170.

8. WHO: Treat 3 million by 2005 -a public health approach for scaling up antiretroviral (ARV) treatment: a toolkit for programme managers. WHO, Geneva 2003, 1-91

9. Lekas H, Siegel K, Schrimshaw E: Continuities and Discontinuities in the Experiences of Felt and Enacted Stigma among Women with HIV/AIDS. Qual Health Res 2006, 16:1165-90.

10. Deribew A, Tesfaye M, Hailemichael Y, Negussu N, Apers L, Colebunders R: TB/HIV co-infection: its impact on Quality of life. Quality of Life and Health Outcomes 2009.

11. Berger B, Ferrans C, Lashley F: Measuring Stigma in People with HIV: Psychometric Assessment of the HIV Stigma Scale. Research in Nursing \& Health 2001, 24:518-529. 
12. Vissel MJ, Makin JD, Vandormael A, Sikkema KJ, Forsyth BW: HIV/AIDS stigma in a South African community. AIDS Care 2009, 21(2):197-206.

13. Thomas BE, Rehman F, Suryanarayanan D, Josephine K, Dilip K, DOrairaj VS, Swaminathan S: How stigmatizing is stigma in the life of people living with HIV: A study on HIV positive individuals from Chennai, South India. AIDS Care 2005, 17(7):795-801.

14. Smith R, Rossetto K, Peterson B: A meta-analysis of disclosure of one's HIV-positive status, stigma and social support. AIDS Care 2008, 20(10):1266-1275.

15. Logie C, Gadalla TM: Meta analysis of health and demographic correlates of stigma towards people living with HIV. AIDS Care 2009, 21(6):742-53.

16. Li Li, Lee S, Thammawijaya P, Jiraphongsa C, Rotheramborus M: Stigma, social support, and depression among people living with HIV in Thailand. AIDS Care 2009, 21(8):1007-13.

17. Dodor EA, Kelly S: 'We are afraid of them': Attitudes and behaviors of community members towards tuberculosis in Ghana and implications for TB control efforts. Psychology, Health \& Medicine 2009, 14(2):170-179.

doi:10.1186/1756-0500-3-249

Cite this article as: Deribew et al:: The synergy between TB and HIV coinfection on perceived stigma in Ethiopia. BMC Research Notes 2010

\section{Submit your next manuscript to BioMed Central} and take full advantage of:

- Convenient online submission

- Thorough peer review

- No space constraints or color figure charges

- Immediate publication on acceptance

- Inclusion in PubMed, CAS, Scopus and Google Scholar

- Research which is freely available for redistribution

Submit your manuscript at www.biomedcentral.com/submit 